\title{
Lectura crítica de Preciados feminismos. Una lectura de Preciado para la antropología filosófica de Mabel A. Campagnoli, Málaga: UMA Editorial, 2018, 456 pág.
}

\author{
Maria Giannoni \\ Universidad de Buenos Aires \\ Facultad de Ciencias Sociales, Argentina \\ giannoni.ma@gmail.com
}

Por muchas razones, Preciados feminismos. Una lectura de Preciado para la antropología filosófica constituye un valioso aporte a los estudios actuales de los feminismos y de la filosofía política contemporánea. La obra $\mathrm{r}$ esume el resultado de los estudios doctorales que Mabel Campagnoli realizó en España, pero da cuenta $t$ ambién de una vasta trayectoria de investigación, docencia y militancia que, como se detalla en las primeras páginas, se inserta en procesos colectivos e institucionales más amplios. En este sentido, es una propuesta t eórica sofisticada y novedosa para una lectura especializada y, a la vez, una muy completa introducción para lector*s interesad*s en las temáticas tratadas.

El libro nos ofrece un análisis crítico de la producción textual del filósofo español Paul B. Preciado, especialmente la que corresponde al período 2000-2010. Su objetivo es mostrar cómo se articulan, en ese corpus, las perspectivas biopolítica y de génerocon sus respectivos recorridos genealógicos. La hipótesis general es que la obra de Preciado resulta de suoriginal apropiación de esas dos tradiciones teóricas y que de esa originalidad pueden derivarse las condiciones para una antropología filosófica no androcéntrica y separada de los mandatos humanistas e ilustrados clásicos. Esa perspectiva antropológica estaría contenida en el potencial emancipatorio de la propuesta de Preciado, fundamentalmente en torno de la idea de contraconducta sexual.En síntesis, el texto se mueve entre la tradición biopolítica y su reelaboración por parte de Preciado como "sexopolítica"; la tradición de pensamiento en torno al género y la categorización de Preciado "dispositivo de género" y, finalmente, la intersección de ambas en la noción de contra-conducta sexual como forma de acción biopolítica afirmativa.

A lo largo del trabajo, tanto el objetivo como la hipótesis se desagregan y precisan en unidades más simples que contribuyen al orden analítico y a la solidez argumentativa de la exposición.

El texto parte de la identificación de los contextos de producción de la obra de Preciado y de su recepción hispanoparlante. La autora ubica la obra en el marco de la tercera ola del feminismo, específicamente en el espacio del "postfeminismo" y de sus líneas internas: teoría queer, cuir y transfeminismos. Aunque la caracterización queer puede ser problemática porque el propio Preciado, a pesar de haberla adoptado en textos tempranos, la encuentra luego inapropiada, su trabajo es heredero indudable del de las principales referentes de la teoría queer, Teresa de Lauretis, Eve Kosofsky Sedgwick y Judith Butler.El aporte principal de este enfoquees la perspectiva deconstructiva sobre el género, a partir de la cual conceptualiza "la dimensión sexual de la identidad colectiva a la vez que señala que la sexualidad no es el único elemento que influye en la configuración de esa identidad" (Campagnoli, 43).

Respecto de la recepción, la autora señala que "en el ámbito iberoamericano Preciado presenta el giro de queer a cuir como un modo de hacer hincapié en el desplazamiento geopolítico hacia el sur", lo cual implica al menos dos cuestiones centrales. Por un lado, significa un corrimiento de la mirada epistemológica colonial y de la historiografía angloamericana que venía dominando los estudios feministas. Y, por otro lado, 
representa la apertura a nuevas formas de prácticas feministas que desbordan las militancias tradicionales y sus premisas políticas, en general ancladas en la diferencia sexual y la identidad de mujer. Estas nuevas militancias se expresan en "laresistencia a la normalización biopolítica de los grupos queer/cuir, transgénero y anticoloniales” (Ibíd, 44). Asimismo, el más reciente término "transfeminismo”acuñado por grupos militantes españoles y latinoamericanos busca, justamente, expresar esa convergencia de feminismos y postcolonialismo a partir de la incorporación del pensamiento de Preciado.

Ligado a lo anterior, es necesario mencionar que el texto asume explícitamente una perspectiva "glo(c)al". El término retoma el pensamiento de Donna Haraway acerca de la necesidad de construir una mirada que cruce lo personal con lo político, propia del feminismo, pero que tambiénempalme lo local y lo global como una "intersección proveniente del postcolonialismo" (Haraway,183-209). Es esta mirada la que encontramos, por ejemplo, en el cuidadoso relevode las primeras referencias a la obra de Preciado en Argentina (trabajos académicos, publicaciones y usosen el ámbito de las militancias), en el recorrido por autor*s e investigaciones de nuestro ámbito y en la permanente remisión a debates coyunturales (prostitución, derechos reproductivos, políticas de identidad, etc.). De esta manera, el trabajo teórico se materializa en reflexiones con valor estratégico e impacto local.

La perspectiva biopolítica de Preciado es presentada como el resultado de un diálogo crítico con la filosofía italiana contemporánea que, a su vez, retoma las tesis foucaultianas acerca del funcionamiento del biopoder en las sociedades modernas. Puntualmente, Campagnoli reconstruye la caracterización del capitalismo contemporáneo por parte de Preciado como una continuidad crítica con el pensamiento de Foucault ycomo una especie de "ajuste" conceptual con las principales tesis del marxismo postobrerista de Negri y Hardt, Lazzarato, Virno, entre otros. Reconstruye en detalle esa doble procedencia que se remonta a las investigaciones de Foucault en torno a la gubernamentalidad y la gestión de la población y a las relecturas postmarxistas de los Grundisse. La inscripción de Preciado en esta tradición aparece articulada alrededor de los conceptos de Sexopolítica e Imperio sexual que aluden, respectivamente, a su apropiación del bagaje foucaultiano y marxista. Pensar la fase actual del capitalismo como sexopolítica, con la modalidad del poder farmacopornográfico que le es inherente, implica incorporar a la idea de biopolítica foucaultiana una precisión técnicasegún la cual el capitalismo contemporáneo no sólo transforma al sexo en el objeto de la gestión política sino que "esta gestión se llevará a cabo a través de las nuevas dinámicas del tecnocapitalismo avanzado" (Preciado, 26-27). La idea de Imperio sexual, por su parte, apunta a mostrar que lo que define la era postfordista no es el trabajo inmaterial o general intellect sino el componente corporal/sexual de la producción. Los términos "general sex", "trabajo sexual” y fuerza orgásmica" terminan de completar esta traducción/sexualización del vocabulario biopolítico. Con ellos seindicael modo en que el sexo se volvió "el correlato del capital" y, por eso mismo, el principal recurso de resistencia y subversión. En este sentido, el esfuerzo del análisis está puesto en explorar el singular significado del término "sexual" en el pensamiento del filósofo. La operación interpretativa de Preciado consistiría, en sacar a la luz la dimensión sexual del orden capitalista del siglo XXI y en elaborar una descripción apropiada de su funcionamiento.

En este punto, resultan especialmente interesantes las páginas dedicadas a la noción de potentia gaudendi o fuerza masturbatoria. Se trata de uno de los conceptos más complejos del trabajo teórico de Preciadopero concentra buena parte de su capacidad explicativa. El análisis de la cuestión ocupa un lugar central y estratégico en la estructura argumental del libro y de ese modo logra mostrar la articulación entre las dos líneas conceptuales que se están considerando - la concepción biopolítica y la concepción del género- al tiempo que habilita la reflexión sobre lo contrasexual.

Una vez redefinido el trabajo como trabajo sexual en el marco de la sexopolítica, la potentia gaudendi traduce la idea marxista de fuerza de trabajo, entendida no ya como cooperación intelectual sino como cooperación masturbatoria o "fuerza orgásmica". En las pocas líneas que refieren a la cuestión en Testo Yonqui (2008), es definida como "la potencia (actual o virtual) de excitación (total) de un cuerpo", como "una capacidad indeterminada" que no tiene género, "no es ni femenina ni masculina, ni humana ni animal, ni 
animada ni inanimada, no se dirige primariamente a lo femenino ni a lo masculino, no conoce la diferencia entre heterosexualidad y homosexualidad, no diferencia entre ser excitado, excitar o excitarse-con" (Preciado, 38). De acuerdo con la interpretación que ofrece Campagnoli, el sentido del término se vuelve más claro cuando se incluye en la definición del poder: "en el capitalismo farmacopornográfico, la fuerza de trabajo ha revelado su verdadero sustrato: fuerza orgásmica, potentia gaudendi" (Ibíd: 38). Es decir, la potentia gaudendi "es el motor vital de toda figura socio-política", es la base de la sexopolítica y aquello que es controlado por el imperio sexual a través de sus dos grandes regímenes de poder, pornográfico y farmacológico (Campagnoli, 271).

Ahora bien, entendida como sustrato, motor vital, vida o cuerpo, queda claro que la potentia gaudendi no se define por un contenido concreto sino por una duplicidad móvil. Ella alude a la materia prima del poder pero, al mismo tiempo, alude a la forma en la que el poder se ejerce dado que, ese ejercicio se mide por la producción del material infinitamente excitable que es el cuerpo sexuado. Se produce así, advierte la autora, una suerte de círculo conceptual: la potentia gaudendi sustrato de los cuerpos sustrato de la potentia gaudendi. Para evitar las evidentes resonancias metafísicas de la fórmulanos propone comprender la relación potentia gaudendicuerpo como la de condición de posibilidad recíproca, "si inteligimos un cuerpo es porque en el soma actuó la inscripción vital de la potentia gaudendi, pero ambas nociones, potencia y soma son distinguibles siempre a posteriori sin constituir a la vez un a priori pre-discursivo" (Campagnoli, 273). La idea de "condición de posibilidad recíproca" tiene el mérito de que antepone el punto de vista de la relación sobre el de los elementos y, de ese modo, anticipa el sentido de la noción de dispositivo de género.

En la conceptualización del género como dispositivo, para Campagnoli confluyentres antecedentes que orbitan constantemente en la obra de Preciado. En primer lugar, la idea recupera el sentido foucaultiano de "producción” y además, como lo sugiere Teresa de Lauretis en la expresión "tecnología del género", tiene la intención de generizar el dispositivo foucaultiano de sexualidad. En segundo lugar, en tanto producido, el género tiene las características performativas que le atribuyeButler dado que es productor, a su vez, del sexo y de la línea de coherencia entre sexo, sexualidad, orientación sexual y deseo. En tercer lugar, encuentra relevante el hecho de que Preciado ponga en conexión dos tradiciones de pensamiento sobre el génerolos discursos médico-psiquiátricos y las ciencias sociales-, desconocidas generalmente por la mayoría de los feminismos.

A partir de lo anterior, la descripción del dispositivo de género se organiza en dosapartados. Uno, corresponde a la exposición de la "episteme post Money-ista", que lo sustenta desde el punto de vista conceptual y remite, precisamente, al uso médico del término por parte de John Money para aludir a la identidad de un individuo independientemente de sus órganos genitales. Otro, corresponde a la descripción del funcionamiento del dispositivo de género centrado en el despliegue conjunto de las formas porno y fármaco del poder.

De esta minuciosa descripción se destaca la reconstrucción del modo en que Preciado elabora la idea del género prostético como una derivación de la idea butleriana de género performativo. Si bien, la idea de prótesis incluye la de performance, la autora llama la atención sobre la utilidad del término butleriano de "quiasmo". Aunque Preciado no lo considera, permite ampliar la caracterización de la producción del género en el interior del farmacopornopoder. La relación quiasmática cuerpo-lenguaje, sostiene, "habilita atender la materialidad en todas sus implicancias institucionales, es decir, incluso los usos del cuerpo intervenido por la medicina y por el ámbito jurídico" (Ibíd, 332). Como vemos, la figura del quiasmo, evoca la ambivalencia y la plasticidad implicadas en la potentia gaudendi como material primario de la manipulación sexopolítica y permitemostrar que la contrasexualidad pertenece a ese mismo espacio sexopolítico y surge de esa misma potencia. Efectivamente, que la performatividad del dispositivo de género sea prostética significaque "las identidades que produce son ficciones somatopolíticas que no pueden desarticularse a través del lenguaje; por lo tanto, las contra-conductas que resistan a sus operaciones, deberán involucrar procedimientos tecnosomáticos que surgen del quiasmo entre soma y discurso" (Ibíd, 335). 
La reflexión sobre la noción de quiasmo le permite a Campagnoli precisar uno de sus señalamientos críticos más importantes. A grandes rasgos, sostiene que en pos de enfatizar el aspecto material/tecnológico de la producción de la subjetividad genérica, Preciadominimiza el aspecto psíquico y/o simbólico de ese proceso. Como consecuencia, maneja una noción de materialidad que parece ser "demasiado concreta o exteriorizante" y produce "un reduccionismo de lo corporal que, si bien puede pensarse como tecnología, no dejaría lugar a procesos mentales de ninguna índole" (Ibíd. 334). Si bien la cuestión se vuelve patente en el contexto de la recepción de Butler y en torno de la producción del género como condición prostética, se incluye en la pregunta general por la relación de Preciado con la teoría psicoanalítica que está presente en todo el texto. La ausencia de enfoques psicoanalíticos es constantemente observada y, en ocasiones, evaluada como una limitación.

Con algunas diferencias, la relación materialidad/lenguaje es analizada por Martín de Mauro Rucovsky en su libro Cuerpos en escena. Materialidad y cuerpo sexuado en Judith ButleryPaul B. Preciado, publicado en Argentina en 2016. El autor entiende que la distancia que Preciado toma de la concepción excesivamente discursiva de Butler es, en realidad, una diferencia de matices que da cuenta de una continuidad entre ambas visiones.

El libro se cierra con un capítulo dedicado a reconstruir la noción de contrasexualidad con la que se vuelve a convocar la herencia biopolítica foucaultiana, esta vez en función de caracterizar las posibilidades de resistencia.Para Preciado la biopolítica deviene sexopolítica y "el modo de resistir sus efectos en función de transformarla positivamente, como reapropiación política por parte de los sujetos sujetados, sería mediante contra-conductas que para el caso resultarían contra-sexuales" (Ibíd, 369).

El análisis distingue dos aspectos de la contrasexualidad. Uno, de carácter teórico y desarrollado fundamentalmente en el Manifiesto contrasexual (2000), consiste en la propuesta de elaborar una dildotectónica destinada a la desnaturalización y deconstrucción del sistema de géneros. Aquí se analizan las prácticas de las comunidades transgénero, como las drag-king y las transformaciones de género clandestinas (autoreguladas por fuera de protocolos médico-jurídicos) como experiencias que materializan la condición artefactual y producida del género. El otro aspecto considerado es el de la autoexperimentación, contenido en Testo Yonqui (2008), y analizado en función de las complejidades que suscita la postulación del ámbito personal como espacio para la acción política y la autoficción. En ambos casos la contrasexualidad es presentada como una dimensión positiva de la sexopolítica y dependiente de los procedimientos tecnológicos provistos por el dispositivo de género.

El itinerario genealógico de este aspecto "positivo" de la biopolítica recoge, nuevamente, los aportes del pensamiento italiano: la idea de noopolítica, formulada por Lazzarato para referir el papel de las nuevas tecnologías en la producción de subjetividad; los conceptos "multitud" y "monstruo político", propuestos por Negri para pensar la oposición al poder como producción a-normal y contraeugenésica; la categoría de "inmunidad" planteada por Esposito y la consecuente diferenciación entre políticas sobre la vida y políticas de la vida.En todos los casos, la confrontación con el poder no está concebida como una oposición frontal sino como una instancia que forma parte de la misma trama del poder que quiere contrarrestar.

Una mirada cercana de la contrasexualidad, se encuentra en interruqciones. ensayos de poética activista, escritura, politica, pedagogía (2013), de la militante y activista argentina valeria flores. La autora reflexiona sobre la posibilidad de una apropiación positiva de las herramientas políticas disponibles para alterar su sentido y desvirtuar sus efectos. En particular, analiza la práctica de escritura como una práctica/saber que "desorienta el orden normativo de lo que se debe hacer - y lo que no- con los cuerpos" (flores, 59). Y, por eso, "escribir es poner un cuerpo. Escribir es poner en acción un cuerpo. Escribir es acción sobre el cuerpo" (flores, 11). En un breve artículo en el que reflexiona sobre la discusión acerca de la legalidad e ilegalidad del aborto, reescrituras del aborto (2010), flores defiende el uso de misoprostol como una forma de agenciamiento de las propias mujeres. Siguiendo a Preciado, entiende que bajo la hegemonía de la industria 
farmacológica, "resulta un potente acto de resistencia el colocar la información del uso de una droga para abortar de modo seguro en manos de las mujeres".

Preciados feminismos explora a fondo el universo filosófico de Preciado, sus antecedentes y sus posibles derivas. Introduce claves de lectura originales y fundamentadas a través del uso de un repertorio abundante de fuentes y referencias bibliográficas actualizadas. Pone a disposición de $l^{*}$ s lector*s una sistematización de los principales problemas, debates y líneas teóricas que atraviesan el campo del feminismo y de la filosofía política actuales.

Nos convoca a una forma de hacer filosofía que no postula metas ni diseña programas de acción; al contrario, afirma que "desde el mismo lugar en que estamos ubicad*s es posible generar desplazamientos, contra-conductas, cambios de sentido que hagan jugar la significación a contracorriente de lo instituido, que innoven".

\section{ReFERENCIAS}

Campagnoli, M. A. (2018). Preciados feminismos. Una lectura de Preciado para la antropología filosófica. Málaga: UMA Editorial.

flores, v. (2013). interruqciones. ensayos depoética activista, escritura, política, pedagogia. Neuquén: La Mondonga Dark. flores, v. (2010) reescrituras del aborto. Recuperado de http://escritoshereticos.blogspot.com.ar/

Haraway, D. (1995). Ciencia, ciborgs y mujeres. La reinvención de la naturaleza. Madrid, Cátedra.

Preciado, B. [P. B.] (2008). Testo Yonqui. Madrid: Espasa-Calpe. 